\title{
Two-Stage TURP as an Option for Treatment of Large Prostates in Resource Poor Environments
}

\author{
Timothy U. Mbaeri, Chinonso Odo, Uchenna V. Nwadi, and Balantine U. Eze
}

\section{ABSTRACT}

\begin{abstract}
Transurethral resection of the prostate (TURP) is the gold standard of surgical therapy of benign prostatic hyperplasia (BPH) for prostates $<100 \mathrm{ml}$. This study was carried out to describe our experience with and outcome of staged TURP for large prostates $(>100 \mathrm{ml})$. A review of the records of all the patients who underwent staged TURP for large BPH at a specialist urology center. They had two-stage monopolar resection using a size $26 \mathrm{~F}$ continuous flow resectoscope and $5 \%$ Dextrose water irrigation. Staged-TURP were performed by a single Consultant Urologist under spinal anesthesia. Patients' age, Co-morbidities, Prostate-specific Antigen (PSA), Abdominal Ultrasound scan (USS) estimated prostate volume, Pre-operative Packed Cell Volume (Pre-op PCV), Post-operative Packed Cell Volume (Post-op PCV), Resection Weight for $1^{\text {st }}$ stage (RW I), Resection Weight for $2^{\text {nd }}$ stage (RW II), Resection Time for $1^{\text {st }}$ stage (RT I), Resection Time for $2^{\text {nd }}$ stage (RT II), blood transfusion were obtained and analyzed. Follow up was for a minimum of 9 months and the outcome and development of complications noted. Statistical analysis was done using the IBM Statistical Package for the Social Sciences (SPSS) version 20.0 (IBM, Chicago, USA). Means and percentages were calculated, and paired sample $T$ test was used to compare variables between $1^{\text {st }}$ stage and $2^{\text {nd }}$ stage. $P$ value $<0.05$ was considered significant. Twenty-five patients with a mean age of $72.32 \pm 7.98$ years were analyzed. Most $(\mathbf{8 8 \%})$ were on indwelling Foley's urethral catheter before surgery. The mean PSA and prostate volume were $25.61 \pm 22.08 \mathrm{ng} / \mathrm{ml}$ and $221.56 \pm 62.78 \mathrm{~cm}^{3}$. There were significant differences between Pre-op PCV and Post-op PCV (p<0.001); RWI and RWII ( $<<0.001)$; and RTI and RTII $(p<0.001)$. Nineteen patients $(76 \%)$ received perioperative transfusion. Most patients voided satisfactorily following catheter removal except one who developed acute urinary retention (AUR). No cases of TUR syndrome, postoperative sepsis, DVT or PE and urethral stricture were recorded. Staged TURP is safe and effective treatment modality for patients with large prostates in the absence of more recent endoscopic options.
\end{abstract}

Keywords: Complications, Large Prostates, Outcome, Staged TURP.
Published Online: July 31, 2021

ISSN: $2736-5476$

DOI: $10.24018 /$ ejclinicmed.2021.2.3.104

\section{T. U. Mbaeri}

Department of Surgery, Nnamdi Azikiwe University Teaching Hospital, Nnewi, Anambra State, Nigeria.

(tu.mbaeri@unizik.edu.ng)

C. Odo

Department of Surgery, Nnamdi Azikiwe

University Teaching Hospital, Nnewi,

Anambra State, Nigeria.

(chinonsoodo940@gmail.com)

U. V. Nwadi

Department of Surgery, Nnamdi Azikiwe

University Teaching Hospital, Nnewi,

Anambra State, Nigeria.

(nwadiuchennavictor@yahoo.com)

B. U. Eze*

Department of Surgery, Enugu State

University of Science and Technology,

Enugu, Enugu State, Nigeria.

(e-mail: balantine.eze@esut.edu.ng)

*Corresponding Author

\section{INTRODUCTION}

Surgery for benign prostatic hyperplasia (BPH) constitutes a significant proportion of the workload of Urological Surgeons. Since the introduction of effective medical therapy, the indications for surgical therapy have dwindled. However, there still exist indications for surgery. These include failed medical therapy, recurrent acute urinary retention, refractory haematuria, impaired renal function or upper urinary tract dilatation, large bladder calculi not suitable for endoscopic treatment and recurrent urinary tract infections [1], [2].

For patients who meet the indications for surgical therapy, transurethral resection of the prostate (TURP) still remains the gold standard [2]. However, this procedure is not recommended for prostate volumes greater than $80-100 \mathrm{mls}$ [3], [4]. This recommendation is based on the fact that a lager prostate will require a longer resection time. The recommended safe resection time is $<90$ minutes as prolonged resection time is associated with more complications including post-operative sepsis, post-operative shock, increased bleeding and requirement for blood transfusion, Transurethral resection (TUR) syndrome and deep venous thrombosis/ pulmonary embolism [5]. For patients with prostate glands $>100 \mathrm{mls}$, recommended options for surgical treatment include open prostatectomy (OP), staged TURP, bipolar transurethral resection of the prostate (b-TURP), laser photo-vaporization of the prostate (PVP) and holmium laser enucleation of the prostate (HoLEP) [4], [6], [7]. Among all these options, HoLEP has been shown by a number of randomized studies to have outcome comparable to open prostatectomy but with better side effect profile [8][10]. 
While TURP is becoming increasingly available in tertiary hospitals in our region, newer technologies (HoLEP, bTURP, PVP) are still largely lacking. Consequently, for large prostatic adenomas (>100 g) the only option available to us is OP or staged TURP. However, we are increasingly being faced with patients with very large adenomas who refuse open prostatectomy but rather prefer to be on catheter. This group has also increased their demand for TURP. For this subset of patients, we offer staged TURP.

The aim of this study is to present our experience with and outcome following staged TURP for benign prostatic hyperplasia for this subset of patients with large prostates.

\section{PATIENTS AND METHODS}

This is a retrospective review of the records of all the patients who underwent staged TURP for large BPH at a specialist urology center in Awka, Anambra State South-East Nigeria between May 2016 and April 2020. Data of all patients diagnosed with $\mathrm{BPH}$ who had a prostate size exceeding 100 grams and had a two-stage TURP were retrieved and used in the study. Excluded from the study were patients that had single-stage TURP as well as those that had channel-TURP for prostate cancer.

The patients all had their glands resected at two stages using a size $26 \mathrm{~F}$ continuous flow resectoscope and monopolar electrosurgical unit with diathermy settings of $125 \mathrm{~W}$ and $60 \mathrm{~W}$ for Cutting and Coagulation, respectively. The intraoperative irrigation fluid was $5 \%$ Dextrose water at a height of $60 \mathrm{~cm}$ above the pubic symphysis. All the operations were performed by a single Consultant Urologist under spinal anaesthesia. First stage resection typically involved the median and left lateral lobes while the anterior and right lateral lobes were reserved for the $2^{\text {nd }}$ stage procedure. All the patients had a 3-way, size $24 \mathrm{~F}$, silicone, Foley's urethral catheter inserted at the end of each of the two stages of the TURP and continuous saline irrigation done. The saline irrigation after the $2^{\text {nd }}$ stage procedure was stopped when the effluent became clear. This was followed by decatheterization 24 hours later. The patients were discharged when they no longer had haematuria and were deemed fit for discharge. The second stage procedure was usually done within one week after the $1^{\text {st }}$ stage, except when patient was not deemed fit for immediate $2^{\text {nd }}$ stage or prefers not to have it done in the same admission.

Patients' data relating to Age, Co-morbidities, Prostatespecific Antigen (PSA), Abdominal Ultrasound scan (USS) estimated prostate volume, Pre-operative Packed Cell Volume (Pre-op PCV), Post-operative Packed Cell Volume (Post-op PCV), Resection Weight for $1^{\text {st }}$ stage (RW I), Resection Weight for $2^{\text {nd }}$ stage (RW II), Resection Time for $1^{\text {st }}$ stage (RT I), Resection Time for $2^{\text {nd }}$ stage (RT II), blood transfusion as well as total duration of post-operative hospital stay were obtained and analyzed. Pre-op PCV was assessed before $1^{\text {st }}$ stage and Post-op PCV assessed 24 hours after $2^{\text {nd }}$ stage.

Patients were also followed up for a minimum of 9 months and the outcome and development of complications noted. Statistical analysis was done using the IBM Statistical Package for the Social Sciences (SPSS) version 20.0 (IBM, Chicago, USA). Means and percentages were calculated, and paired sample $\mathrm{T}$ test was used to compare variables between $1^{\text {st }}$ stage and $2^{\text {nd }}$. $P$ value $<0.05$ was considered significant.

\section{RESULTS}

Twenty-five patients aged 55 - 95 years had 2-stage TURP for BPH during the period under review. The mean age was $72.32 \pm 7.98$ years. Prior to surgery most $(88 \%)$ of the patients were on indwelling Foley's urethral catheter for recalcitrant acute urinary retention (Table I). The most common comorbidity among the patients was hypertension (52\%). Others were diabetes mellitus (4\%), and cerebrovascular accident $(4 \%)$ (Table I).

The serum total PSA ranged from $2.12-95.80 \mathrm{ng} / \mathrm{mL}$ with a mean of $25.61 \pm 22.08 \mathrm{ng} / \mathrm{ml}$. The volume of prostate on ultrasound scan ranged from $144.0-386.0 \mathrm{~cm}^{3}$ with a mean of $221.56 \pm 62.78 \mathrm{~cm}^{3}$. The mean time interval between $1^{\text {st }}$ and $2^{\text {nd }}$ stage was $24.68 \pm 41.36$ days with a range of 2-150 days and median interval of 4 days.

The pre-op PCV of the patients ranged $27-43 \%$ with a mean of $36.75 \pm 4.68 \%$. The post-op PCV ranged from 28 $38 \%$ with a mean of $31.95 \pm 2.47 \%$. Nineteen patients were transfused with blood peri-operatively. Seven (28\%) of them received 1 unit of blood, $11(44 \%)$ received 2 units and a patient $(4 \%)$ received 3 units. The mean blood transfusion was $1.28 \pm 0.77$ units of blood. The mean pre-op PCV was significantly higher than that of post-op PCV ( $\mathrm{p}<0.001)$ as shown on Table II.

The RW I ranged from 28.18-100.30 g with a mean of $62.04 \pm 20.93 \mathrm{~g}$ while the RW II ranged from 18.55-72.20 $\mathrm{g}$ with a mean of $35.89 \pm 15.38 \mathrm{~g}$ (Fig. 1). The mean RW I was significantly greater than that of RW II $(\mathrm{p}<0.001)$ as shown on Table II. The RT I ranged from 67.00-106.00 minutes with a mean of $82.88 \pm 10.99$ minutes while the RT II ranged from 41.00-102.00 minutes with a mean of $66.54 \pm 18.77$ minutes (Fig. 1). The mean RT I was significantly more than that for RT II $(p<0.001)$ as shown on Table II. The total duration of post-operative hospital stay ranged from 2-9 days with a mean of $5.64 \pm 2.04$ days. Most patients voided satisfactorily following catheter removal except one who developed acute urinary retention (AUR).

Complications were noted in 6 patients who underwent the procedures. Capsular perforation occurred in one patient, epididymorchitis occurred in 2 patients, secondary haemorrhage in one patient, incontinence in one patient and AUR in one patient. No cases of TUR syndrome, postoperative sepsis, DVT or PE and urethral stricture were recorded.

TABLE I: DISTRIBUTION OF SOME VARIABLES

\begin{tabular}{cccc}
\hline S/N & Variable & Options & Frequency $(\%)$ \\
\hline \multirow{2}{*}{1.} & \multirow{2}{*}{ Foley catheter } & Yes & $22(88)$ \\
& & Nil & $3(12)$ \\
\hline \multirow{2}{*}{2.} & Co-morbidity & Hypertension & $13(52)$ \\
& & Diabetes & $1(4)$ \\
& & Nil & $1(4)$ \\
& & & $12(48)$ \\
\hline
\end{tabular}




\begin{tabular}{ccccc}
\multicolumn{5}{c}{ TABLE II: COMPARISON OF MEAN VALUES OF VARIABLES } \\
\hline S/N & Variable & Mean \pm SD & T & p-value \\
\hline \multirow{2}{*}{1.} & RW I & $62.04 \pm 20.93 \mathrm{~g}$ & \multirow{2}{*}{5.978} & $<0.001$ \\
& RW II & $35.89 \pm 15.38 \mathrm{~g}$ & & \\
2. & RT I & $82.88 \pm 10.99 \mathrm{~min}$ & \multirow{2}{*}{5.145} & $<0.001$ \\
\multirow{2}{*}{3.} & RT II & $66.54 \pm 18.77 \mathrm{~min}$ & & \\
& Pre-op PCV & $36.75 \pm 4.68 \%$ & \multirow{2}{*}{6.333} & $<0.001$ \\
\hline
\end{tabular}

RW I= Resection Weight for $1^{\text {st }}$ stage; RW II= Resection Weight for $2^{\text {nd }}$ stage; RT I= Resection Time for $1^{\text {st }}$ stage; RT II= Resection Time for $2^{\text {nd }}$ stage.

\begin{tabular}{|c|c|}
\hline Complications & Frequency (\%) \\
\hline Capsular perforation & $1(4 \%)$ \\
\hline Epididymorchitis & $2(8 \%)$ \\
\hline Secondary haemorrhage & $1(4 \%)$ \\
\hline Incontinence & $1(4 \%)$ \\
\hline AUR & $1(4 \%)$ \\
\hline Total & $6(24 \%)$ \\
\hline
\end{tabular}

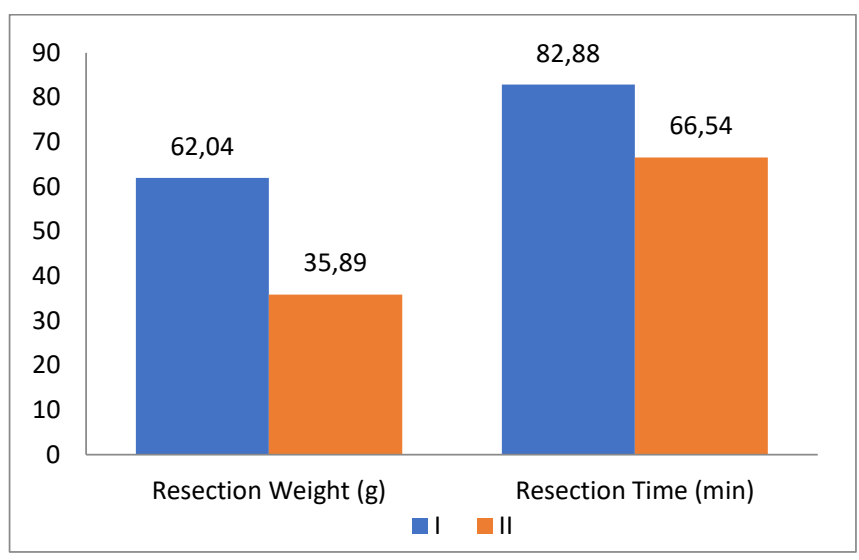

Fig. 1. Comparison of Mean Values of Resection Weight and Time.

\section{DISCUSSION}

Benign prostatic hyperplasia constitutes a major proportion of diagnoses made at urologic consultations. Its surgical management modalities continue to evolve with modifications aimed at improving outcome whilst reducing potential complications and side effects. Patients tend to opt for the least invasive surgical modalities with the best outcome, least complication rate and shortest hospital stay.

The mean age of 72.32 years in this study is similar to 70.1 years reported by Palmisano et al [11] in Italy and comparable to those documented by earlier studies in our region [11], [12]. This goes to support the fact that $\mathrm{BPH}$ is a disease of the ageing male population.

Advance in age is associated with increased incidence of comorbidities which could adversely affect the outcome of surgical intervention. Hypertension was the most common comorbidity noted in this study which supports the findings by other studies [13], [14]. Prior to surgery, majority (88\%) of the patients were on indwelling catheter due to recalcitrant acute urinary retention and obstructive nephropathy which is similar to the $83.1 \%$ documented by Alhasan et al [15] in Nigeria while at variance with the $51 \%$ observed by Marmiroli et al [16] in Brazil. This difference in the rates of use of indwelling catheters, as a temporizing measure, between these study groups could be reflective of their rates of acceptability of surgery as a treatment option. Individuals of African descent are less likely than whites and Hispanics to undergo surgery for BPH when offered [14]. Another factor that contributed to high percentage of urethral catheterization in this study is the fact that our patients refused open prostatectomy which is the commonly available procedure for large glands.

None of the patients in the index study had a prostate volume of less than $100 \mathrm{~g}$. The largest prostate in this study was $386 \mathrm{~cm}^{3}$ and the mean prostate volume was $221.56 \mathrm{~cm}^{3}$. These are far larger than the $150 \mathrm{~cm}^{3}$ and $95 \mathrm{~cm}^{3}$ reported as the largest and the mean prostate volumes, respectively, by Persu et al [17] in Romania in a comparative analysis of TURP and OP for prostates over $80 \mathrm{~cm}^{3}$. The large prostate volumes noted in the index study are not unconnected with the fact that men of African descent tend to have larger BPH [18], [19] and the sample of men involved in this study is those with large prostate glands. The serum Total PSA of the patients ranged from 2.12 to $95.80 \mathrm{ng} / \mathrm{mL}$ with a mean of $25.61 \mathrm{ng} / \mathrm{mL}$ and these reflect the large prostate volumes seen among the patients. Chukwujama et al [19] in Southeastern Nigeria noted a mean PSA of $13.3 \mathrm{ng} / \mathrm{mL}$ and a mean prostate volume of $59 \mathrm{~g}$. These contrasts could be explained by the fact that the patients used in their study had relatively smaller prostate volumes compared to those in our study, and thus lower mean PSA.

In the index study RT I was significantly more than RT II similar to the observation made by Persu et al [20] in an analysis of men who underwent two-stage TURP in Romania. As expected, the RW I was significantly greater than RW II in our study as the weight of resected tissue is a function of the pre-operative prostate volume as well as the duration of resection [21]. Thus, more volumes were extirpated in the $1^{\text {st }}$ stage procedures. The mean RW I of $62.04 \mathrm{~g}$ noted in our study is similar to a mean resection weight of $59.8 \mathrm{~g}$ recorded by Alhasan et al [15] in Northern Nigeria for patients who underwent single stage procedures but much higher than a mean resection weight of $35.3 \mathrm{~g}$ found by Nnabugwu et al [21] in Southern Nigeria. This difference in resected weight between our study (mean prostate volume $=222.56$ ) and that by Nnabugwu et al. (mean prostate volume $=72.3$ ) is not surprising since resected weight is known to strongly correlate with preoperative prostate volume [21].

Transurethral resections of the prostate and bladder are known to be complicated by transurethral resection (TUR) syndrome which is characterized by adverse effects in the cardiovascular and nervous systems arising from excessive absorption of hypotonic irrigation fluid [3], [22]. As a potentially lethal complication of TURP, it requires early diagnosis and aggressive therapy. None of the patients in the index study had TUR syndrome similar to what was found by earlier studies [15], [23]. This, however, is at variance with the $10 \%$ and $23.5 \%$ incidence rates of TUR syndrome documented by George et al [24] in India and Nakahira et al [22] in Japan. Incidence rates of 2\%, 3.2\% and 4.8\% were documented by Persu et al [17] in Romania, McGowanSmyth et al [25] in the United Kingdom and Chukwujama et al [19] in Nigeria, respectively. Management of this complication hinges on its prevention. In fact, the main reason we performed staged procedures for these patients is to limit the complications associated with prolonged resection time including TUR syndrome and excessive haemorrhage. This is important as earlier study has reported that prolonged resection time greater than 90 minutes is associated with 
increased rates of complications [7].

The introduction of staged TURP at our facility at this point is quite timely. This is important as these patients with large prostate volumes rejected open prostatectomy, and instead opted for prolonged urethral catheterization with monthly changes. This explains the high rate of urethral catheterization (88\%) among the study participants. With staged TURP these patients became catheter free with resolution of their lower urinary tract symptoms.

All the patients, except one, in the index study had a successful trial without catheter (TWOC) at the end of their treatment with satisfactory voiding and no need for surgical revision. Successful TWOC at the end the treatment was believed to be the result of complete resection. Aiming to achieve complete resection in these patients with large prostate size was one of the reasons for performing a staged procedure in this study. Duration of post-operative hospital stay is a function of duration of catheterization following TURP. This study recorded a mean of total post-operative hospital stay of 5.64 days which is quite comparable to a mean post-operative hospital stay of 3.8 days earlier observed by us in a previous study of patients who had single stage procedures in the same region [26]. Apparently, those patients had smaller sized prostates (mean prostate volume of $97.43 \mathrm{~g}$ ) and smaller mean resected weights compared to those in the index study. Mean hospital stay of 7.9 and 8.7 days were earlier reported in Nigeria [15], [19]. Mean duration of hospital stay of less than 2 days was noted in a study by Rahman et al [27] in Bangladesh similar to an observation made in India by Khan [28] who also observed that day case TURP was feasible in single stage procedures. However, the patients used in his study had small sized glands with consequent smaller resection volumes and relatively shorter resection times.

Perioperative blood transfusion was administered in $76 \%$ of the patients in this study. This is high but could be explained by the large size of the adenomas. An earlier study [26] in our region evaluating the complications of TURP reported a transfusion rate of $11.34 \%$ (11/97), however the mean prostate volume of the study participants was 97.43 which is much lower than 222.56 in this study. This observation supports the fact that prostate volume may affect rate of bleeding and therefore the transfusion rate during TURP. In addition, pre-operative PCV was significantly higher than post-operative PCV $(\mathrm{p}<0.001)$ in this study. This is despite perioperative blood transfusion and variable time interval between $1^{\text {st }}$ stage and $2^{\text {nd }}$ stage procedure. Doing a two staged procedure would have given some time for replenishment of some blood especially for those with a long interval ( $>2$ weeks) between the stages.

A total of 6 patients developed complications in this study, giving a complication rate of $24 \%$. This complication rate is similar to $24.74 \%$ reported by us in men who underwent single stage TURP in the same region [26]. For the patient that developed capsular perforation, the procedure was rapidly concluded, securing complete haemostasis and bladder irrigation performed at the barest minimum needed. The patients that developed acute epididymorchitis were successfully treated with antibiotics with complete resolution of symptoms. In the patient that developed AUR following catheter removal, catheter was re-passed for an additional one week following which symptoms resolved completely. A patient developed urinary incontinence following catheter removal. This was managed with Kegel's exercises and resolved after a 2-month interval. Finally, one patient developed secondary haemorrhage that was effectively managed with clot evacuation, bladder irrigation and antibiotics therapy.

Urethral stricture is the most common late complication of TURP [29]. For patients with larger preoperative prostate volume (prostate volume $>70 \mathrm{ml}$ ), there is a significantly lower rate of urethral stricture $(\mathrm{p}=0.012)$ in those that had monopolar TURP than those that had bipolar-TURP [30]. In this study, there was no case of urethral stricture recorded despite having to repeat the urethral instrumentation with the resectoscope twice. We were able to achieve this by electively caliberating the urethra to 30 French with an Ottis urethrotomy and generous lubrication of the urethra before insertion of the resectoscope.

\section{CONCLUSION}

In environment like ours where newer technologies are still lacking, two staged TURP is an effective treatment options in patient with glands larger than $100 \mathrm{~g}$. This is particularly important if such patients decline open prostatectomy. By significantly decreasing resection time, this technique efficiently decreases the incidence of serious side effects like TUR syndrome and other perioperative complications.

\section{REFERENCES}

[1] Madersbacher S, Alivizatos G, Nordling J, Sanz CR, Emberton M, De La Rosette Jean J M C H, EAU 2004 guidelines on assessment, therapy and follow-up of men with lower urinary tract symptoms suggestive of benign prostatic obstruction (BPH guidelines). Eur Urol. 2004; 46(5):547-554.

[2] Reich O, Gratzke C, Stief CG. Review-Bladder Outlet Obstruction Techniques and Long-Term Results of Surgical Procedures for BPH. Eur Urol. 2006;49(2006):970-978.

[3] Stolzenburg J-U, Ho KM., Schwalenberg T, Hohenfellner R. Transurethral Resection of the Prostate. In: Manual Endourology. 2005. p. 77-87.

[4] Lee A, Lee HJ, Foo KT. Can men with prostates sized $80 \mathrm{~mL}$ or larger be managed conservatively? Investig Clin Urol. 2017;58(5):359-364.

[5] Riedinger CB, Fantus RJ, Matulewicz RS, Werntz RP, Rodriguez JF, Smith ND. The impact of surgical duration on complications after transurethral resection of the prostate: an analysis of NSQIP data. Prostate Cancer Prostatic Dis. 2019 May;22(2):303-3088.

[6] Gupta NP, Nayyar R. Management of large prostatic adenoma: Lasers versus bipolar transurethral resection of prostate. In: Indian Journal of Urology. Wolters Kluwer -- Medknow Publications; 2013. p. 225-235.

[7] Mehmet Yucel, Bekir Ara, Soner Yalcinkaya, Namik Kemal Hatipoglu and Erol Aras. Conventional monopolar transurethral resection of the prostate in patients with large prostate ( $\geq 80$ grams). Cent European J Urol. 2013; 66(3): 303-308

[8] Kuntz RM, Lehrich K, Ahyai SA. Holmium Laser Enucleation of the Prostate versus Open Prostatectomy for Prostates Greater than 100 Grams: 5-Year Follow-Up Results of a Randomised Clinical Trial. Eur Urol. 2008;53(1):160-168.

[9] Naspro R, Suardi N, Salonia A, Scattoni V, Guazzoni G, Colombo R, et al. Holmium Laser Enucleation of the Prostate Versus Open Prostatectomy for Prostates $>70$ g: 24-Month Follow-up. Eur Urol. 2006;50(3):563-568.

[10] Zhang Y, Du C-J, Xu G, Chen J-M, Jing X. Transurethral holmium laser enucleation for prostate adenoma greater than $100 \mathrm{~g}$. Zhonghua Nan Ke Xue. 2007;13(12):1091-1093.

[11] Palmisano F, Boeri L, Fontana M, Gallioli A, De Lorenzis E, Zanetti $\mathrm{SP}$, et al. Incidence and predictors of readmission within 30 days of transurethral resection of the prostate: A single center European experience. Sci Rep. 2018; 8(1):1-7. 
[12] Oranusi C, Nwofor A, Mbonu O. Correlation between internationa prostate symptom score and uroflowmetry in patients with benign prostatic hyperplasia. Niger J Clin Pract. 2017; 20:454-458.

[13] Salako AA, Badmus TA, Owojuyigbe AM, David RA, Ndegbu CU, Onyeze CI. Open Prostatectomy in the Management of Benign Prostate Hyperplasia in a Developing Economy. Open J Urol. 2016; 06(12):179-189.

[14] Gill H. Racial Disparities in the Treatment of Benign Prostatic Hyperplasia. Med Surg Urol. 2015;4(4):157.

[15] Alhasan SU, Aji SA, Mohammed AZ, Malami SS. Transurethral resection of the prostate in Northern Nigeria, problems and prospects. BMC Urol. 2008; 8(1):18.

[16] Marmiroli R, Antunes AA, Reis ST, Nakano E, Srougi M. Standard surgical treatment for benign prostatic hyperplasia is safe for patients over 75 years: Analysis of 100 cases from a high-volume urologic center. Clinics. 2012 Dec;67(12):1415-1418.

[17] Persu C, Georgescu D, Arabagiu I, Cauni V, Moldoveanu C, Geavlete P. TURP for BPH. How large is too large? J Med Life. 2010;3(4):376380.

[18] Fowler JE, Bigler SA, Kilambi NK, Land SA. Relationships between prostate-specific antigen and prostate volume in black and white men with benign prostate biopsies. Urology. 1999;53(6):1175-1178.

[19] Chukwujama, Oguike T, Azike J. Transurethral resection of the prostate a 3 year experience. Niger J Surg. 2011; 17(1):15-18

[20] Kaplan SA, Reis RB, Staimen VB, Te AE. Is the ratio of transition zone to total prostate volume higher in African-American men than in their Caucasian or Hispanic counterparts? British Journal of Urology. 1998, 82:804-807

[21] Nnabugwu II, Ugwumba FO, Udeh EI, Ozoemena OF. Learning transurethral resection of the prostate: A comparison of the weight of resected specimen to the weight of enucleated specimen in open prostatectomy. Niger J Clin Pract. 2017; 20(12):1590-1595.
[22] Nakahira J, Sawai T, Fujiwara A, Minami T. Transurethral resection syndrome in elderly patients: a retrospective observational study. $B M C$ Anaesthesiol. 2014;12:30.

[23] Akpayak I, Shuaibu S, Onowa V, Nabasu L, Galam Z. Monopolar transurethral resection of the prostate for benign prostatic hyperplasia: What are the outcomes and complications in our patients? Niger J Med. 2017;26(2):173

[24] George C, Haque PD, Mammen KJ. Incidence, clinical manifestations and outcome of TUR (transurethral resection) syndrome in patients undergoing TURP under spinal anaesthesia: results from clinica observations in a cohort of 50 patients at a tertiary care centre in North India. Int Surg J. 2017; 5(1):243-247.

[25] McGowan-Smyth S, Vasdev N, Gowrie-Mohan S. Spinal Anesthesia Facilitates the Early Recognition of TUR Syndrome. Curr Urol. 2015;9(2):57-61.

[26] Mbaeri, Abiahu JA, Obiesie EA, Odo C, Oranusi KC, Nwofor AME, et al. Assessment of complications of transurethral resection of the prostate using Clavien-Dindo classification in South Eastern Nigeria. Niger J Surg. 2020; 26(2):142-146.

[27] Rahman MM, Gupta SD, Mridha NI, Wahid M, Begum F. Comparative Study Between Outcome of Early and Conventional Catheter Removal After Transurethral Resection of Prostate. Bangladesh J Urol. 2017;20(2):82-86.

[28] Khan A. Day care monopolar transurethral resection of prostate: Is it feasible? Urol Ann. 2014;6(4):334-339.

[29] Nielsen KK, Nordling J. Urethral stricture following transurethra prostate prostatectomy. Urology. 1990 Jan 1;35(1):18-24.

[30] Komura K, Inamoto T, Takai T, Uchimoto T, Saito K, Tanda N, Minami K, Oide R, Uehara H, Takahara K, Hirano H. Incidence of urethral stricture after bipolar transurethral resection of the prostate using TURis: results from a randomised trial. BJU Int. 2015 Apr 1;115(4):644-652 